\title{
COMO A DIFERENÇA PASSA DO CENTRO À MARGEM NOS CURRÍCULOS: O EXEMPLO DOS PCN*
}

\author{
ElizABETH MACEDO
}

\begin{abstract}
RESUMO: O texto parte do pressuposto de que os estudos de política curricular centrados no Estado empobrecem a análise por não darem conta da relação entre estrutura e agência. Apoia-se na teoria discursiva de E. Laclau e C. Mouffe para analisar as políticas curriculares como articulaçóes hegemônicas em torno do preenchimento do significante qualidade da educação. Centra-se na análise dos Parâmetros Curriculares Nacionais, especialmente os de Ciência e os Temas Transversais, tendo como foco articulaçóes universalistas que buscam minar as demandas da diferença. Considerando que essas articulaçôes podem ser percebidas pela análise dos textos curriculares tais como enunciados, a autora destaca duas estratégias utilizadas nos PCN: a criação de dois componentes curriculares, com a localização das demandas da diferença no menos institucionalizado deles; e as lutas por hegemonia no interior desse componente.
\end{abstract}

Palavras-chave: Currículo. Política de currículo. Diferença. Parâmetros Curriculares Nacionais. Ciências.

\section{HOW DIFFERENCE MOVES FROM THE CENTER TO THE MARGINS:} THE CASE OF BRAZILIAN NATIONAL CURRICULUM

ABSTRACT: This paper assumes that the analysis of the curriculum policy is weakened by a state-centered model that cannot correctly address the relationship between structure and agency. Based on E. Laclau's and C. Mouffe's discursive theory, it analyzes the curriculum

Texto vinculado ao projeto "Currículo de ciências: uma abordagem cultural", financiado pelo CNPq e pela FAPERJ, e a projeto de pós-doutorado financiado pela CAPES.

* Doutora em Educação e professora da Universidade do Estado do Rio de Janeiro (UERJ). E-mail: bethmacedo@pobox.com 
policy to show they are hegemonic articulations to fill up the empty signifier "quality of education". It examines the Brazilian National Curriculum, especially the Science and the Transversal Themes components, focusing on how universalistic articulations try to undermine the demands of difference. Considering that such articulations may be spotlighted in the way these curriculum texts were enunciated, it highlights two major strategies used in the National Curriculum: its division into two components, the less institutionalized one containing the demands of difference; and the struggles to control this latter component from within.

Key words: Curriculum. Curriculum policy. Difference. Brazilian national curriculum. Science curriculum.

Como a diferença passa do centro à margem nos currículos: o exemplo dos PCN de Ciências

s anos de 1990, no Brasil, foram marcados pela centralização das políticas curriculares, aqui entendida não apenas como a proposição de currículos nacionais, mas como uma ação articulada que envolveu o controle da avaliação e dos livros didáticos. Como reação a essa centralização, o debate acadêmico ampliou-se, dominado por críticas aos princípios neoliberais aplicados na formulação das políticas. Tanto a centralização das políticas como a proliferação de estudos que denunciavam a ação do Estado não constituem movimentos ocorridos apenas no Brasil, a julgar pela literatura internacional (Pinar, 2003; Whitty et al., 1999; Apple, 1994). O país inseria-se em um movimento mais amplo, cujo ícone talvez tenha sido a Inglaterra de Thatcher, não propriamente pela magnitude das reformas aí introduzidas, mas pela importância desse governo na reorganização das forças políticas internacionais (Hall, 2003). No geral, o debate estabelecido na ocasiāo (Gentili, 1996; fE/UfrGS, 1996; Moreira, 1996) passava por cima das múltiplas formas que assumiam as políticas, salientando as semelhanças, o papel de um Estado coeso em torno do ideário neoliberal e as vinculações entre economia e políticas públicas.

Tendo em vista que essa produção proliferou num cenário internacional em que os Estados ampliavam seu controle e diminuíam suas responsabilidades de investimento, parece fácil entender que as análises tivessem o intervencionismo estatal como foco. No entanto, estudos da 
produção menos claramente vinculada ao burburinho do momento (Macedo et al., 2006; Paiva et al., 2006; Oliveira, 2006) demonstram que a centralidade do papel do Estado tem sido a tônica da produção sobre políticas de currículo. Trata-se de uma característica que também não parece ser exclusividade do Brasil (Ball, 1994 e 2006; Taylor et al., 1997).

Ao defender que grande parte dos estudos sobre política de currículo se centra na ação do Estado estou me arriscando numa generalização questionável. Por um lado, deixo de citar trabalhos em que a heterogeneidade das políticas é destacada (Candau, 1999; Lopes, 2006; Fleuri, 2002; Oliveira, 2005) e, por outro, aproximo estudos cujo foco é o Estado com aqueles em que o econômico tem primazia. Em relação a este último aspecto, não pretendo matizar as muitas formas que pode assumir a análise de políticas centrada no Estado (Oliveira, 2006) e apoio-me em Ball (2006) e Taylor et al. (1997) para simplesmente considerar que se pode falar em um modelo de análise com foco no estatal. Meu pressuposto, neste texto, é de que esse modelo tem empobrecido as análises das políticas de currículo, na medida em que o foco na estrutura dificulta a percepção das lutas hegemônicas travadas nas diferentes instâncias em que se dá a política como processo. A ação dos sujeitos é relegada ao segundo plano e professores, alunos e comunidade são vistos como meros destinatários de políticas centralizadas.

Buscando fazer face ao que entendo ser um limitador nas análises das políticas curriculares, tenho trabalhado com a teoria do discurso de Laclau e Mouffe (Laclau \& Mouffe, 1985; Laclau, 1998 e 2000), que entendo permite melhor conceptualizar a relação entre estrutura, posiçôes de sujeito e agência. A teoria, baseada em ideias pósestruturais, defende que as posiçôes de sujeito são relacionais e não possuem nenhum significado transcendental, inclusive os determinados por estruturas sociais ou econômicas. Isso não significa que a estrutura não existe, mas apenas que ela não determina posições sociais. Defendo que essa abordagem não-determinística apresenta boas possibilidades para o estudo das políticas curriculares, permitindo fugir tanto da ideia de determinação estrutural quanto de concepçôes voluntaristas.

\section{Pensando as políticas curriculares como articulaçōes hegemônicas}

Laclau e Mouffe (1985) utilizam a noção de estrutura de Saussure para defender que, numa estrutura aberta, sempre existe algo 
que não pode ser simbolizado. Toda estrutura, além de diferencial, é deslocada e é esse deslocamento que revela o seu limite e contingência e impede o seu completo fechamento. Apresenta, portanto, um excesso de sentido que sempre escapará e que constitui o discursivo como campo de indecidibilidade, condição e impossibilidade de tentativas de fixação de sentido, ou seja, de cada discurso particular. Uma estrutura de tal forma deslocada não tem objetividade e, portanto, não é capaz de determinar posições de sujeito, que passam a ser descritas como significantes flutuantes.

Para evitar uma posição relativista, Laclau e Mouffe (1985) consideram que a estrutura pode ser fechada momentaneamente, mas mantém sua posição antiessencialista afirmando que o fechamento não pode se justificar por nenhuma essência. Ele será sempre produzido por intervençôes hegemônicas capazes de, contingencialmente, posicionar determinados significantes como pontos nodais em relação aos quais os demais são definidos. A existência de um ponto nodal implica que o caráter meramente diferencial do sistema seja atravessado por uma lógica de equivalência, que guarda com ele uma relação de indecidibilidade. A lógica da equivalência é criada pela presença de uma diferença radical, um exterior constitutivo que fecha momentaneamente o sistema e cria uma cadeia de equivalência entre os seus elementos diferenciais, que passam a se articular também de forma não-diferencial. Em função do exterior constitutivo, com sua lógica de antagonismo radical, os elementos do sistema passam a partilhar algo comum, a diferença radical em relação a esse exterior, que lhes permite uma articulação de equivalência em torno dos significantes nodais.

Se a existência de relações antagônicas condiciona a estabilidade e o deslocamento da estrutura, as posições de sujeito não podem ser objetivas. Os sujeitos sociais são internos à estrutura deslocada e sua incorporação à ordem simbólica demanda identificações contingentes. É essa incorporação que, para Laclau (1998), cria os sujeitos como locus da decisão no espaço indecidível da estrutura deslocada, uma decisão sobre como se constituir a si próprios como subjetividades concretas.

Zizek (2000) introduz o conceito de falta constitutiva de Lacan para entender a relação entre estrutura e posições de sujeito. Todo sujeito procura por um significante que possa expressá-lo dentro da ordem simbólica, num ato de significação que nunca será totalmente 
possível. ${ }^{1} \mathrm{O}$ sujeito busca por intermédio de atos de significação preencher uma falta constitutiva; ele entra na relação antagônica com a esperança de que, aniquilando o adversário, possa estabelecer a identidade plena que lhe é negada. Portanto, é o sujeito que tenta resolver a crise da estrutura deslocada por sua identificação com um dos projetos disponíveis no espaço indecidível dessa estrutura. Assim, não é a estrutura que define as posiçôes de sujeito, mas o sujeito que, ao decidir por uma posição de sujeito, articula a estrutura.

Como há muitas e contraditórias posiçôes de sujeito possíveis, a solução da crise da estrutura deslocada sempre envolve articulações hegemônicas contingentes. Pressionados por um exterior constitutivo, diferentes posições de sujeito tentam preencher o significante vazio que funciona como ponto nodal que organiza a estrutura. Dessa forma, posições hegemônicas funcionam como mitos que visam preencher a estrutura deslocada, conseguindo fazê-lo apenas parcialmente e por um tempo, até que são confrontados com novos eventos não-simbolizáveis. As relações hegemônicas "não são [, portanto,] totalidades autorreguladas, mas articulações precárias que estão sempre ameaçadas por um exterior constitutivo" (Laclau, 2000, p. 231). Nelas, identidades particulares buscam hegemonizar o lugar vazio do universal, de modo que "as estratégias criam identidades e não ao contrário” (idem, ibid., p. 243).

Ser hegemônico envolve falar em nome de um objeto universal impossível (a sociedade, por exemplo), muitas vezes à custa de demandas particulares. Essas demandas precisam ser esvaziadas de sentido, transformadas num significante vazio, o único capaz de encarnar a completude ausente. O conteúdo literal dos discursos é suprimido em favor de uma dimensão metafórica que condensa diferentes sentidos. Que discursos se tornam hegemônicos é função das capacidades dos discursos plurais de se oferecer como resposta à crise social, de operar como um espaço de inscrição das demandas dos diferentes grupos, de compensar o deslocamento da estrutura social. Butler (1997) sugere que a superioridade de um discurso é também devida às ligações que ele pode estabelecer com sentidos residuais - a possibilidade de se referir a uma época de ouro.

Julgo que a impossibilidade de fechamento simbólico do social, tal como apresentada por Laclau e Mouffe (1985), é uma ferramenta teórica útil para o estudo das políticas de currículo. Em minhas análises, 
tenho considerado que a noção de qualidade da educação vem funcionando como ponto nodal que organiza os discursos pedagógicos e justifica a necessidade das reformas curriculares. Essa noção, tal como acontece com qualquer ponto nodal, é um significante vazio que lutas hegemônicas tentam preencher. Nesse processo, a presença de um exterior constitutivo, representada pela ineficiência do sistema educacional (pela ausência de qualidade), articula discursos vários e cria um híbrido de diferentes posições de sujeito. Argumento que cadeias de equivalências são criadas, incluindo fragmentos de diferentes discursos, como solução para a propalada crise educacional. Chamo a atenção de que elas não são, no entanto, uma conseqüência da crise, uma vez que essa crise cria as cadeias de equivalências, mas define-se pela expansão dessas mesmas cadeias. Assim como ocorre com o conceito de qualidade, a atual ineficiência do sistema educacional não tem nenhum significado específico, significado este que é criado pela expansão das cadeias de equivalências.

Nas múltiplas articulações hegemônicas para preencher o significante vazio qualidade da educação, há cadeias de equivalências específicas, que lidam com as demandas de grupos minoritários pelo reconhecimento da diferença, que me interessa destacar. Ainda que a ideia de miscigenação racial tenha feito parte da própria definição de identidade nacional, mais recentemente temos lidado com os ecos das políticas de identidade, especialmente em função das reivindicações dos movimentos negros. A lei da igualdade racial, o reconhecimento de Zumbi dos Palmares como herói nacional, a implementação de ações afirmativas nas universidades e no setor público, a inclusão de História da África nos currículos escolares são alguns exemplos das mudanças que vimos tendo nos últimos anos. As posições de sujeito ligadas aos movimentos negros têm sido posições-chave na luta pelo reconhecimento da diferença, no entanto suas demandas precisam ser ampliadas para incluir outras diferenças como forma de garantir hegemonia.

Essa expansão das cadeias de equivalências, que aproxima as reivindicaçóes dos vários grupos dentro dos movimentos negros e destes com outros movimentos sociais, é possível em função de um exterior constitutivo bem sedimentado no imaginário brasileiro. Refirome ao mito da democracia racial, associado em uma ampla cadeia com a ideia de nação, também ela um conceito muito sedimentado nas sociedades ocidentais. Essa pressão antagônica ameaça as cadeias 
em torno da diferença e torna sua expansão uma necessidade, tal como é claramente enunciado no Relatório para o Desenvolvimento Humano que, em 2005, foi dedicado ao racismo:

(...) para enfrentar os desafios inerentes à mudança de quase cinco séculos de dominação racial no Brasil, amplas alianças precisam ser forjadas. Só assim será possível fazer com que a igualdade de oportunidades e a reparação da injustiça contra a população negra deixem de ser questão do negro e passem a ser um objetivo nacional permanente. (PNUD, 2005, p. 58)

O documento explicita algumas estratégias usadas na expansão das cadeias de equivalências em torno da diferença. Ainda que as estatísticas mostrem que a redução da pobreza, na década de 1990, atingiu apenas os não-negros (PNUD, 2005), a articulação entre significantes de raça e classe tem se constituído numa das estratégias de sua ampliação hegemônica. Exemplo claro no campo da educação são os pré-vestibulares para negros e carentes: vinculado a movimentos iniciados pela Pastoral do Negro para ampliar o número de negros nos cursos superiores, passa a se redefinir em 1994 como um Movimento Social de Educação Popular, ainda que a questão do preconceito racial continue explicitada como a sua principal preocupação. Essa expansão lança mão, ela mesma, de uma representação que vem suportando o mito da democracia racial: a ideia de que o preconceito no Brasil não é racial, mas social. As políticas da diferença utilizam, tentando subvertê-lo, parte de um mito bem sedimentado que lhes serve de antagonista. A expansão custa, portanto, aos movimentos negros parte de suas próprias demandas.

Não apenas raça, mas outras posições de sujeito têm tomado parte nas cadeias de equivalências em torno da noção de diferença. No entanto, não as explorarei aqui, na medida em que meu objeto não é a expansão de discursos da diferença, mas a rearticulação que eles vêm provocando em algumas cadeias antagônicas constituídas em torno do ponto nodal qualidade. Mais especificamente no que concerne ao currículo, tenho percebido que uma das estratégias dessa rearticulação tem sido a defesa de conteúdos de cunho universalista, apresentados como garantia de qualidade da educação e, portanto, como ferramenta de igualdade social. A alusão à necessidade de serviços públicos universais de qualidade nos setores de educação, que apareceu por exemplo no manifesto de (autodenominados) intelectuais contra o sistema de cotas, é um poderoso rearticulador do discurso universalista. Num país em que parte 
considerável da população vive em condições econômicas desfavoráveis, esse tipo de proposta é compreensível, ainda que impacte negativamente as lutas em torno da diferença. Dessa forma, o mito da igualdade racial, que veio se desgastando nas últimas décadas, é substituído pela ideia de que as políticas públicas não devem priorizar grupos específicos, mas garantir mínimas condições e iguais oportunidades a toda a população.

No que respeita aos discursos pedagógicos, a tese de que a educação somente será igualitária se garantir a todos o domínio de conteúdos universais vem sendo defendida pela pedagogia histórico-crítica há anos. Saviani, por exemplo, já em 1983, comentava, ao criticar o escolanovismo:

(...) contra essa tendência de aligeiramento do ensino destinado às camadas populares, nós precisamos defender o aprimoramento exatamente do ensino destinado às clamadas populares. Essa defesa implica a prioridade de conteúdo. Os conteúdos são fundamentais e, sem conteúdos relevantes, conteúdos significativos, a aprendizagem deixa de existir, ela se transforma num arremedo (...). A prioridade nos conteúdos é a única forma de lutar contra a farsa do ensino. Por que esses conteúdos são prioritários? Justamente porque o domínio da cultura constitui instrumento indispensável para a participação política das massas. (p. 59)

Essa tese vem, a meu ver, ganhando ressonância nos textos curriculares recentes, apesar do destaque que vem sendo dado à pluralidade cultural do país em documentos datados dos anos de 1990 (Macedo et al., 2006). Também no âmbito teórico, a defesa de conteúdos universais vem ganhando adeptos. Moreira (2004), um forte crítico da pedagogia histórico-crítica (1989), por exemplo, defende em texto intitulado "Por que ter medo dos conteúdos?":

(...) sugiro que a supervalorização do aluno e do conhecimento, que venho encontrando no discurso de propostas curriculares oficiais alternativas, e a consequente secundarização do conhecimento escolar (restrito a instrumento para a formação plena do estudante) podem ajudar a criar um "compartimento" no qual esse estudante, que tanto de deseja promover, seja situado e visto sempre como "diferente", incapaz de aprender conteúdos formais das disciplinas científicas, possivelmente úteis à tarefa do "desencaixe" a ser retomada na contemporaneidade. (p. 40)

Não apenas esses discursos alicerçados em pressupostos críticos, mas também discursos conservadores e ligados ao mercado têm 
participado de uma cadeia de equivalências em torno da qualidade da educação centrada no domínio de conteúdos disciplinares universais ou de saberes socialmente organizados. Entendo que a articulação desses discursos tem sido possível em função de um exterior constitutivo relacionado à pressão das demandas da diferença sobre a escola e o currículo, também elas articuladas em função do antagonismo radical de discursos universalizantes. Dessa forma, tanto uma como outra cadeia de equivalências, em processos de articulação e rearticulação hegemônicos, tentam preencher o significante qualidade, o que só são capazes de fazer provisoriamente.

Neste texto, aproximo-me dessas articulações e rearticulações na análise dos Parâmetros Curriculares Nacionais, destacando os fragmentos de discursos pedagógicos mobilizados pelos documentos curriculares, obviamente não os entendendo como dissociados de outros discursos sociais, mas como posicionalidades em cadeias de diferenças e equivalências que se interconectam com outras cadeias discursivas. Trabalho a partir de posicionalidades estabelecidas no interior de discursos pedagógicos porque julgo que estes têm sido, estranhamente, esquecidos nas análises de políticas curriculares. Considero que os discursos pedagógicos trazem posições de sujeitos que lutam por hegemonia nas novas enunciações curriculares e julgo que a compreensão dessas lutas permite "configurar a resposta do campo a suas circunstâncias presentes e sociais" (Pinar, 2007, p. 5). Trabalho com o pressuposto de que é possível acessar as articulações e rearticulações que ocorrem na enunciação dos currículos pela releitura do texto. Centro-me, como venho fazendo nos últimos anos, no componente curricular Ciências e em sua relação com os Temas Transversais. Ainda que haja algumas diretrizes comuns nos PCN para todas as disciplinas, e diversos documentos disciplinares partilhem discursos pedagógicos semelhantes, entendo que o currículo é uma enunciação que acontece em contextos cotidianos específicos, de modo que não é possível transpor sentidos entre diferentes componentes curriculares. Entendo que as comunidades disciplinares que participam da elaboração de cada um dos documentos hibridizam crenças partilhadas ao tentar dar sentido à qualidade.

$\mathrm{O}$ argumento que espero ter construído até aqui é que as demandas da diferença têm acirrado uma cadeia de equivalências entre discursos universalistas ${ }^{2}$ que visam a preencher o significante vazio qualidade da educação. Em relação aos currículos, essa cadeia tem se 
alicerçado sobre a defesa de conteúdos tradicionalmente neles presentes, frequentemente associados à ideia de que os campos de conhecimento têm algo que lhes é próprio. No entanto, esse discurso tem de negociar sua existência com as demandas da diferença que também têm conquistado seu espaço nos currículos. Para manter sua hegemonia nessa conjuntura, as cadeias universalistas têm lançado mão de uma série de estratégias para se apresentar como solução para a atual (e de sempre) crise do sistema educacional. Dentre essas estratégias, destacarei, no que tange aos PCN, duas que me parecem muito fortes. A primeira é a divisão do currículo em dois componentes, as disciplinas escolares e os Temas Transversais, com a migração das demandas da diferença para o menos institucionalizado dos componentes. A segunda é constituída por um movimento para controlar o espaço marginal dos Temas Transversais, um território disputado por vários discursos pedagógicos.

\section{Deslocando a diferença para a margem: disciplinas e Temas Transversais}

Uma das estratégias utilizadas nos PCN para garantir a hegemonia de cadeias universalistas ao mesmo tempo em que incorporam demandas da diferença é a divisão do currículo em dois componentes. A partir da existência desses dois componentes, a disciplina Ciências pode responder a essas demandas apenas mencionando-as e remetendo-as aos Temas Transversais. Mantém, assim, seu compromisso com "os conteúdos formais das disciplinas científicas" (Moreira, 2004, p. 40 ), o saber iluminista que a tem caracterizado e cuja hegemonia vem sendo garantida, ao longo dos séculos, pela difusão da cultura europeia (Laclau, 2000).

Ao buscar preencher o significante qualidade, os PCN de Ciências defendem o ensino ativo, baseado na observação, na experimentação e nos jogos. A ineficiência das experiências curriculares atuais, em contrapartida, é relacionada a uma pedagogia tradicional e ao ensino enciclopédico, supostamente dominante na educação em Ciências. Essa ineficiência funciona como um exterior constitutivo que permite a hibridação de fragmentos de diferentes discursos pedagógicos e de discursos sobre a Ciência.

Considerando os discursos pedagógicos, os PCN de Ciências hibridizam fragmentos do progressivismo, da aprendizagem significativa 
de Ausubel, do modelo da mudança conceitual, do currículo centrado na disciplina, do ensino pelo método científico e da pedagogia histórico-crítica. Ainda que tais discursos sejam muito diferentes nos contextos em que foram (inicialmente) enunciados, eles podem ser articulados numa cadeia de equivalências na medida em que a ineficiência da educação tradicional funciona como exterior constitutivo. O híbrido enunciado não tem relação necessária com os sentidos originais de cada fragmento, é o produto contingente de articulaçôes hegemônicas entre diferentes posições de sujeito (pedagógicas).

O discurso sobre a educação em Ciências emerge dessa articulação como uma tentativa de preencher o significante vazio qualidade e aponta para uma concepção universalista de conhecimento, ainda que abra espaço para demandas recentes da diferença. Os princípios norteadores da elaboração curricular são o respeito ao desenvolvimento cognitivo dos alunos, a contextualização e a consideração das experiências prévias dos estudantes. Os sujeitos são claramente apresentados como indivíduos não contextualizados e suas experiências social e cultural são valorizadas como ponto de partida para a construção de um saber científico e universal. O interesse dos estudantes, suas concepçôes prévias ou seu conhecimento sincrético passam a participar de uma cadeia de equivalentes e são considerados "interpretaçôes ingênuas da realidade" (Brasil, 1998a, p. 35) que precisam ser superadas. O conhecimento científico ou socialmente elaborado é a chave para "construir explicaçôes, mediadas pela interação com o professor e outros estudantes e pelos instrumentos culturais próprios do conhecimento científico" (idem, ibid., p. 28). A contextualização é, portanto, apenas uma estratégia para a aprendizagem significativa e implica a desvalorização do saber contextual na medida em que ele é considerado primitivo e oposto à ciência entendida como a narrativa dos povos civilizados. Os discursos pedagógicos vão sendo mobilizados constituindo, por meio de cadeias de equivalências, um documento híbrido que privilegia a dimensão científica dos conteúdos como aquela que dará acesso à compreensão "real" do mundo.

A forma como é enunciado esse discurso pedagógico híbrido encontra ressonância na concepção de ciência, na qual novamente se pode observar uma complexa tentativa de inserir o discurso universalista. A concepção de ciência universal prevalece, sem que haja qualquer 
questionamento sobre as estratégias por meio das quais a ciência ganhou sua mobilidade. É também verdade, no entanto, que os PCN da disciplina introduziram uma preocupação com aspectos culturais ligados à ciência. A própria definição de ciência como uma produção humana e uma recriação cultural que acontece em contextos sociais específicos - "a Ciência deve ser apreendida em suas relaçôes com a tecnologia e com as demais questões sociais e ambientais" (Brasil, 1998a, p. 21) - deixa claro como as demandas da diferença vêm penetrando nos currículos escolares mesmo em campo historicamente avesso às intervençôes culturais. Trata-se, no entanto, de uma produção histórica que, por seguir padrões de validação universais (definidos pelo método científico ou por uma comunidade científica livre de conflitos), é capaz de produzir um conhecimento mais verdadeiro. Neste sentido, uma epistemologia internalista reforça o universalismo. A historicidade e a vinculação social do conhecimento científico são traduzidas pelo fato de que a ciência oferece respostas às demandas históricas de uma sociedade. Assim, as tecnologias do período Paleolítico ou da Pedra Polida foram tão universais nesses períodos como o são hoje os produtos científicos e tecnológicos - "produtos científicos e tecnológicos é algo hoje universal” (idem, ibid., p. 22).

A cadeia que privilegia a concepção universal de conhecimento precisa, no entanto, responder também às demandas em torno da diferença, especialmente aquelas apresentadas em eixos temáticos que se justificam pela relevância social, ${ }^{3}$ como ocorre com o eixo "Ser Humano e Saúde". A concepção de saúde expressa no documento dá conta de que a temática apresenta dimensões biológicas, mas também socioeconômicas, culturais, psíquicas e políticas. Neste sentido, o PCN explicita que o homem de que está falando é um sujeito concreto que habita uma comunidade ou nação e que vive num contexto local: "para que o aluno compreenda a integridade do corpo, é importante estabelecer relaçôes entre os vários processos vitais, e destes com o ambiente, a cultura ou a sociedade" (Brasil, 1998a, p. 45). Essa concepção sociocultural que norteia parte do documento negocia seu espaço no terreno marcado pelo discurso universalista da ciência. Ao mesmo tempo em que, no eixo Ser Humano e Saúde, é ressaltado que "o aprendizado científico (...) é um aprendizado integrado aos conhecimentos culturais" (idem, ibid., p. 46), a ciência é a detentora das respostas corretas: "reconhecer as noções trazidas pelo aluno, reinterpretá-las, valorizá-las 
e combater equívocos graves com argumentos objetivos é parte deste aprendizado" (idem, ibid.).

Essa tensão é também visível na abordagem do tema sexualidade neste mesmo eixo. Os PCN chamam a atenção para o fato de que no corpo "estão inscritas a história de vida, a cultura, os desejos e as aprendizagens do indivíduo" (Brasil, 1998a, p. 51), definindo a sexualidade como algo que envolve "fatores biológicos, culturais, sociais e de prazer" (idem, ibid., p. 47), não se restringindo à reprodução. No PCN de Ciências, no entanto, assumem centralidade a reprodução (especialmente a indesejada) e as formas de evitá-la, assim como a prevenção de doenças sexualmente transmissíveis. Embora enfatize que o ser humano vive num mundo social que é dinâmico - abrindo espaço para a consideração da "diversidade [que] torna a experiência humana mais rica, quanto menos se estiver preso a estereótipos de comportamento e quanto mais houver tolerância com pessoas e grupos diferentes de si mesmo" (idem, ibid., p. 78) -, o privilégio da dimensão biológica é inegável.

Nesses e em outros exemplos, percebe-se como concepções universalistas de conhecimento se articulam em uma cadeia de equivalências que se apresenta como garantia de um ensino de qualidade. Essa cadeia incorpora tanto discursos pedagógicos univesalistas quanto uma concepção de ciência que, se não é imune à cultura, deixa claro que relaçôes desse tipo são localizadas fora do âmbito da ciência como conhecimento. A pressão dos grupos não-hegemônicos, no entanto, tensiona todo o tempo esse discurso universal, chamando a atenção para o sujeito concreto que habita um lugar instável numa cadeia de posições de sujeito sempre em mutação. Dessa forma, tais grupos buscam também preencher o significante qualidade, tendo suas demandas insinuadas no currículo de Ciências, mas remetidas aos Temas Transversais, especialmente os denominados "saúde", "pluralidade cultural", "meio ambiente" e "orientação sexual". Nesse processo de deslocamento das demandas contextuais para um lugar especial do currículo, menos formal, reforça-se o poder simbólico do conhecimento universal.

A Nova Sociologia da Educação já analisou exaustivamente as relações entre disciplinas escolares formalmente estabelecidas no currículo e aquelas marcadas pela fragilidade institucional - não avaliadas em exames nacionais (ou vestibulares), não presentes na grade horária, 
sem livros didáticos ou corpo de docentes com formação específica. Não pretendo retomar aqui tais análises, mas perceber essa divisão como um mecanismo discursivo regulatório para reconhecer a diferença ao mesmo tempo em que a repele.

O saber contextual é definido pelo conhecimento universal hegemônico como seu negativo e essa definição é repetida exaustivamente como um mecanismo para estereotipá-la. A insistência da cadeia universal em descrever os conhecimentos dos alunos como ponto de partida nomeando-os como concepções prévias, conhecimento não-significante ou concepção sincrética do mundo - mostra como é importante nomear o outro. A própria existência dos Temas Transversais pode ser vista como um exemplo dessa importância. $\mathrm{Na}$ verdade, eles não são nada além de um lugar para onde o outro pode ser repelido e nomeado como algo diferente do conhecimento iluminista universal. Por essa prática de nomear, busca-se fixar o outro conhecimento fora da cadeia de equivalências em torno da qualidade.

Essa estratégia pode ser vista como parte de uma fantasia de completude que nunca poderá ser completa. $\mathrm{O}$ conhecimento universal repele o outro para perceber-se como completo, mas o ato da repulsão permanece como um testemunho de sua incompletude. É por isso que sua superioridade, que seria óbvia se realmente existisse, precisa ser constantemente relembrada. A fantasia universal (colonial?) assenta-se na impossível distinção entre conhecimento iluminista (conteúdos escolares) e os conhecimentos contextuais trazidos à escola por alunos, professores, comunidades, numa fantasia de origem. Como ressalta Zizek (2000), a fantasia de completude não se refere apenas ao conhecimento, na medida em que podemos saber que há outros sistemas de conhecimento, mas agimos como se eles não existissem. A fantasia é sobre agir como se os sistemas totalizantes (como o saber universal) fossem únicos, ainda que saibamos que eles não o são. Isso funciona como uma compensação na medida em que as pessoas não estão realmente convencidas da universalidade do conhecimento. A fantasia esconde, portanto, o antagonismo presente em todo espaço social e a lacuna aberta por esse deslocamento no social é localizada nos outros. Outros que são a expressão da parte má do social, mas são também um objeto de fascinação posto que representam a possibilidade da completude impossível. 
Há ambivalência na relação entre discursos universalistas e demandas da diferença numa articulação que envolve repulsão e atração. Não é, portanto, suficiente empurrar as demandas da diferença para o lugar do Outro, mas é preciso também controlar (colonizar) esse lugar. Passo a explorar como cadeias discursivas universalistas tentam controlar, de dentro, o espaço marginal dos Temas Transversais.

Controlando as margens: lutas hegemônicas dentro dos Temas Transversais

Ainda que, por sua menor formalização, os Temas Transversais assumam o lugar do Outro nos PCN, nos últimos dez anos esse componente curricular veio se institucionalizando por mecanismos alternativos. De forma semelhante ao que ocorre nos documentos disciplinares, eles também são apresentados como capazes de preencher o significante vazio qualidade da educação. Ainda que seu status teórico não seja bem definido, são descritos como tratamento didático capaz de promover um conhecimento mais integrado com a vida social. Desse modo, não se legitimam pela referência à ciência, mas pela aplicabilidade e pelo caráter político do conhecimento. Mais uma vez, o sistema educacional atual, de enfoque eminentemente disciplinar, é descrito como exterior constitutivo, num discurso que acaba sendo o reverso do apresentado para legitimar as disciplinas:

Amplos o bastante para traduzir preocupações da sociedade brasileira de hoje, os Temas Transversais correspondem a questões importantes, urgentes e presentes sob várias formas na vida cotidiana. (...) O presente texto apresenta a concepção de cidadania e os princípios democráticos que a norteiam, discute a amplitude do trabalho com questôes sociais na escola e apresenta a proposta em sua globalidade. (Brasil, 1998b, p. 17)

Ainda que as demandas da diferença sejam, em sua ampla maioria, encaminhadas para esse componente curricular, nele também os saberes contextuais têm de negociar espaço com cadeias universalistas que se formam em torno, especialmente, da promessa de educar para a cidadania. Tal promessa está na base do que os Temas Transversais definem como educação de qualidade e funciona como um forte legitimador de sua inserção nos PCN. O que se entende por cidadania, no entanto, espelha a ambiguidade de diferentes projetos educacionais que 
disputam espaço em articulaçôes hegemônicas. Como destacam Taylor et al. (1997) e Labaree (1997), três grandes narrativas buscam justificar o projeto educativo - social ou edificadora do nacional, econômica e relacionada ao desenvolvimento individual - e podemos vê-las mescladas no documento ao definir cidadania. O conceito de cidadania desliza, assim, entre essas narrativas, por vezes salientando o caráter público da educação, em outras tratando-a como bem privado (Macedo, 2000).

Destaco que, nos PCN, a cidadania é ligada a discursos fortemente sedimentados e isso ajuda a garantir legitimidade não apenas à educação para a cidadania, mas aos próprios Temas Transversais. Por um lado, os documentos vinculam cidadania à nação, um dos conceitos que, se vem sendo posto em questấo recentemente, consolidou-se ao longo da Modernidade no imaginário ocidental. Por outro, no que diz respeito às vinculaçôes pedagógicas, aludem ao progressivismo, à pedagogia de Freire e à pedagogia histórico-crítica, todas elas tradições que contam com uma aura positiva ligada à equidade e ao respeito pelo conhecimento dos alunos. Por fim, a referência ao trabalho e à inserção no mercado de consumo dialoga com os anseios de promoção social, uma das grandes promessas do capitalismo, assim como, paradoxalmente, com as crenças marxistas na centralidade do trabalho (Macedo, 2007; Marcondes, Tura \& Macedo, 1999). Ainda que aluda a um cidadão universal, esse conjunto de referências não é contraposto nos Temas Transversais às demandas da diferença. Ao contrário, o documento define a Nação como plural, enunciando princípios como dignidade humana, igualdade de direitos, participação e corresponsabilidade. Os sujeitos são reconhecidos como tendo direitos e "a definição de quem é ou deve ser reconhecido como sujeito de direito é [considerada] social e histórica" (Brasil, 1998b, p. 19).

Essa enorme amplidão de posições presentes no documento é o que Laclau e Mouffe (1985) têm entendido como a criação de cadeias de equivalências a partir das quais as posições, que se mantêm diferentes, articulam-se em função de um exterior constitutivo que as ameaça. Tal cadeia é possível na medida em que os "sentidos originais" de cada um dos fragmentos são tornados difusos na própria articulação, o que possibilita ao currículo, tal como enunciado, articular novos sentidos, criando outros endereçamentos para os sujeitos. No caso dos Temas 
Transversais, entendo que esses novos sentidos apontam para uma cidadania nacional e, por vezes, global, que se propóe a englobar a diferença.

Os Temas Transversais tentam operar, na definição de cidadania e identidade nacional, com a ilusão de que é possível falar em nome de um coletivo do qual nada se exclui:

Apesar da discriminação, da injustiça e do preconceito que contradizem os princípios da dignidade, do respeito mútuo e da justiça, paradoxalmente o Brasil tem produzido também experiências de convívio, reelaboração das culturas de origem, constituindo algo intangível que se tem chamado de brasilidade, que permite a cada um reconhecer-se como brasileiro. (Brasil, 1998b, p. 121)

Assim, a diferença é transformada em um dos ícones da nacionalidade, de uma nação baseada "na tolerância, no respeito aos direitos humanos universais e da cidadania compartilhada por todos os brasileiros" (Brasil, 1998b, p. 69). Toda nação, no entanto, repousa sobre uma homogeneidade primordial e é produto do apagamento das diferenças enquanto tal, com a criação de ícones e símbolos que fabricam pertencimentos. Historicamente, vincula-se à estrutura e aos conceitos dos discursos de raça, na medida em que se baseia na coesão dentro de suas fronteiras e numa diferenciação entre o dentro e o fora. No Brasil, no entanto, o discurso da nacionalidade tem incorporado a diferença como uma de suas marcas. Trata-se, no entanto, de uma incorporação da diferença como o discurso do mesmo que tenta esconder a arbitrariedade com que são definidas as regras de pertencimento. Assim, as diferenças culturais são, paradoxalmente, reconhecidas e assimiladas ao todo homogêneo da nação.

O conceito de nação, que Bauman (2005) descreve como o mais sólido princípio usado para associar sujeitos a seus lugares de nascimento, é um dos pontos nodais das democracias modernas (Laclau, 2000). Trata-se de um poder simbólico e invisível que unifica a sociedade e constitui as pessoas que imaginam tal poder como cidadãos. Educar para a cidadania é, portanto, uma tentativa de preencher o significante vazio de nação com um discurso que fala em nome de toda a sociedade. Como sistema simbólico, no entanto, a nação não pode ser plenamente constituída. Não importa quão exaustiva seja a definição da cidadania brasileira, sempre haverá algumas características (de 
certos grupos) que vão escapar. Unificar um conceito de nação implica ter um exterior constitutivo, um inimigo real ou imaginário que culpamos por ter roubado a Coisa nacional como forma de "escondermos o fato de que nunca tivemos o que é dito que foi roubado de nós” (Zizek, 1990, p. 57). Portanto, o conceito de nação, por mais que se defina como plural, não pode incluir a todos porque depende, para se estabilizar, da construção de um Outro. Dessa forma, educar para a cidadania é falar em nome de uma totalidade impossível, de um universal que, como todo universal, constitui-se com base em exclusões.

Nesse sentido, entendo que, ao preencher o significante qualidade com a promessa de educar para a cidadania, os Temas Transversais jogam as demandas da diferença para a margem numa articulação que permite o controle desse espaço, já em si marginal, por discursos universalistas. Claro que esse endereçamento não é absoluto, convivendo com as ambivalências da própria enunciação da Nação, tal como apontadas por Bhabha (2003). E possível, portanto, que "formas de identidade cultural e solidariedade política emerjam das temporalidades disjuntivas da cultura nacional” (p. 214). Ainda que essas possibilidades de fuga existam no horizonte de minhas esperanças e sejam o próprio sentido da escrita deste texto, não as tratei aqui porque entendo que a cidadania nacional, como mito, ${ }^{4}$ ainda é um forte articulador do discurso universalista nos Temas Transversais.

\section{Conclusão}

As duas estratégias de articulação hegemônica em torno do significante qualidade da educação utilizadas nos PCN para deslocar as demandas da diferença para a margem não são as únicas postas em curso por cadeias universalistas. Para além da defesa de conteúdos comuns, de base científica ou expressão do saber socialmente acumulado, e de políticas públicas que privilegiam princípios entendidos como igualitários, outras formas de anular os discursos da diferença aparecem em diferentes documentos curriculares e merecem ser estudadas. Lembrome, aqui, por exemplo, da estratégia de definir a diferença como diferença individual que analisei em relação à "Multieducação" (Macedo, 2005) e que poderia também ter sido objeto de discussão neste texto no que tange aos PCN. Não pretendi, no entanto, ser exaustiva em relação a 
essas estratégias até porque as entendo como articulações móveis que se dão num terreno movediço que sempre está a nos apresentar outras possibilidades de análise.

Minha denúncia das estratégias utilizadas pelas cadeias universalistas no sentido de continuar garantindo sua hegemonia nada tem a ver com a defesa do particularismo. Em outra direção, entendo que o caminho para um currículo centrado na diferença é desconstruir a dicotomia entre particular e universal, percebendo este último como lugar vazio preenchido temporariamente por articulações hegemônicas. Julgo que o primeiro passo neste sentido é explicitar as estratégias utilizadas por discursos universalistas para se apresentarem como o Universal. Estratégias que se modificam constantemente, até porque são construídas nos contextos de articulação, mas que em geral se baseiam em alguma característica positiva associada àquilo que se deseja universalizar. Neste sentido, entendo que esse exercício que venho fazendo de analisar como as cadeias universalistas vêm buscando garantir sua hegemonia nos currículos é uma forma de ação política, na medida em que nos permite indagar sobre como constituímos estruturas de poder por intermédio do posicionamento de sujeitos no interior contestado dessas estruturas. Uma ação que julgo mais efetiva do que a possível com modelos de análise que optam por uma concepção verticalizada de poder.

Recebido em novembro de 2007 e aprovado em abril de 2008.

\section{Notas}

1. A ordem simbólica é atrapalhada pelo Real lacaniano que introduz uma perturbação que resiste à totalização e, assim, desloca a estrutura. Essa negatividade radical impedirá que o sujeito encontre um significante por meio do qual possa expressar-se. Isso faz com que o ato de simbolização falhe e produza a falta que é precisamente o sujeito. Neste sentido, o sujeito significante será a falta, um efeito retroativo da impossibilidade de sua própria representação (Torfing, 1999).

2. Não questiono a existência de um universal, mas o seu preenchimento por discursos que se apresentam como donos inquestionáveis desse lugar. Entendo, como Laclau (2000), que o lugar do universal é preenchido provisoriamente por discursos particulares. O que chamo de discursos universalistas são particulares que buscam se naturalizar na posição de universal frequentemente pela alusão a alguma característica que lhes é essencial.

3. O documento de Ciências é organizado em torno de quatro eixos temáticos, justificados ora pelas especificidades da disciplina, ora pela atualidade e importância das temáticas.

Educ. Soc., Campinas, vol. 30, n. 106, p. 87-109, jan./abr. 2009 
Como a diferença passa do centro à margem nos currículos: o exemplo dos PCN

4. Quando falo em cidadania como mito quero sublinhar que se trata de um discurso em que se busca controlar as fugas de sentido, ou seja, a dimensão performática de que fala Bhabha (2003).

\section{Referências}

APPLE, M. A política do conhecimento oficial: faz sentido a idéia de um currículo nacional? In: Moreira, A.F.B.; Silva, T.T. (Org.). Currículo, cultura e sociedade. São Paulo: Cortez, 1994. p. 59-92.

BALL, S. Educational reform: a critical and post-structural approach. Buckingham: Open University, 1994.

BALL, S. Sociologia das políticas educacionais e pesquisa crítico-social: uma revisão pessoal das políticas educacionais e da pesquisa em política educacional. Currículo sem Fronteiras, v. 6, n. 2, p. 10-32, jul./dez. 2006. Disponível em: <www.curriculosemfronteiras.org>. Acesso em: 15 nov. 2007.

BAUMAN, Z. Identidade. Rio de Janeiro: Zahar, 2005.

BHABHA, H. O local de cultura. Belo Horizonte: UfMG, 2003.

BRASIL. Ministério da Educação. Parâmetros Curriculares Nacionais: ciências. Brasília, DF: MEC, 1998a.

BRASIL. Ministério da Educação. Parâmetros Curriculares Nacionais: temas transversais. Brasília, DF: MEC, 1998b.

BUTLER, J. Excitable speech: a politics of performative. New York: Routledge, 1997.

CANDAU, V.M.F. Reformas educacionais hoje na América Latina. In: Moreira, A.F.B. Currículo: políticas e práticas. Campinas: Papirus, 1999. p 29-41.

FLEURI, R.M. A questão da diferença na educação: para além da diversidade. In: REUNIĀO ANUAL DA ANPED, 25., 2002, Caxambu. Anais... Rio de Janeiro: DP\&A, 2002. Disponível em: <www.anped.org.br>.

GENTILI, P. Neoliberalismo e educação: manual do usuário. In: SILVA, T.T.; Gentili, P. Escola S.A. Brasília, DF: CNTE, 1996. p. 9-49. 
HALL, S. Da diáspora: identidades e mediações culturais. Belo Horizonte: UFMG, 2003.

LABAREE, D.F. How to suceed in school without really learning. New Haven: Yale University, 1997.

LACLAU, E. Desconstruccion, pragmatismo, hegemonia. In: Mouffe, C. Desconstruccion y pragmatismo. Buenos Aires: Paidós, 1998. p. 97-136.

LACLAU, E. Nuevas reflexiones sobre la revolución de nuestro tiempo. Buenos Aires: Nueva Visión, 2000.

LACLAU, E.; MOUFFE, C. Hegemony and socialist strategy. London: Verso, 1985.

LOPES, A.C. Discursos nas políticas de currículo. Currículo sem Fronteiras, v. 6, n. 2, p. 33-52, jul./dez. 2006. Disponível em: <www.curriculosemfronteiras.org>. Acesso em: 15 nov. 2007.

MACEDO, E. Formação de professores e diretrizes curriculares nacionais: para onde caminha a educação? Teias, Rio de Janeiro, v. 1, n. 2, p. 7-19, jul./dez. 2000.

MACEDO, E. Diferença cultural e conhecimentos acumulados: conversas a partir da multieducação. In: Pereira, M.Z.; Moura, A.P. Políticas e práticas curriculares: Impasses, tendências e perspectivas. João Pessoa: Idéia, 2005. p.107-138.

MACEDO, E. et al. Currículo da Educação Básica. Brasília, DF: MEC/ INEP, 2006.

MACEDO, E. Science curriculum in Brazil: how does difference goes from the center to the margin? In: ANNUAL MEETING AAACS, 2007, Chicago: AAACs, 2007. Anais... Disponível em: <www.aaacs.org>.

MARCONDES, M.I.; TURA, M.L.; MACEDO, E.F. Parâmetros Curriculares Nacionais: uma análise dos conceitos cidadania, qualidade e diversidade cultural. Educação em Questão, Natal, v. 8/9, n. 1/2, p. 59-81, 1999.

MOREIRA, A.F.B. Currículos e programas no Brasil. Campinas: Papirus, 1989. 
MOREIRA, A.F.B. Os parâmetros curriculares nacionais em questão. Educação \& Realidade, Porto Alegre, v. 21, n. 1, p. 9-22, jan./abr. 1996.

MOREIRA, A.F.B. Por que ter medo dos conteúdos? In: Pereira, M.Z.; Moura, A.P. Políticas e práticas curriculares: impasses tendências e perspectivas. João Pessoa: Idéia, 2004. p. 11-42.

OLIVEIRA, I.B. Currículos praticados: entre a regulação e a emancipação. Rio de Janeiro: DP\&A, 2005.

OLIVEIRA, O.V. O processo de produção da política de currículo em Ribeirão Cascalheira-MT (1969-2000). 2006. 232f. Tese (Doutorado) Faculdade de Educação, Universidade do Estado do Rio de Janerio, Rio de Janeiro.

PAIVA, E.V. et al. Políticas curriculares no foco das investigações. In: Lopes, A.C.; Macedo, E. (Org.). Políticas de currículo em múltiplos contextos. São Paulo: Cortez, 2006. p. 241-269.

PINAR, W. International handbook of curriculum research. New Jersey: Lawrence Elrbaum, 2003.

PINAR, W. Intellectual advancement through disciplinarity: verticality and horizontality in curriculum studies. [S.1.]: Sense, 2007. Disponível em: <http://csics.educ.ubc.ca/>. Acesso em: 15 nov. 2007.

PNUD. Relatório de Desenvolvimento Humano: racismo, pobreza e violência. Brasília, DF, 2005. Disponível em: <www. pnud.org.br>. Acesso em: 15 nov. 2007.

SAVIANI, D. Escola e democracia. São Paulo: Cortez, 1983.

TAYLOR, S. et al. Educational policy and the politics of change. London: Routledge, 1997.

TORFING, J. New theories of discourse: Laclau, Mouffe and Zizek. Oxford: Blackwell, 1999.

UNIVERSIDADE FEDERAL DO RIO GRANDE DO SUL. Faculdade de Educação. Parecer sobre os Parâmetros Curriculares Nacionais. Educação \& Realidade, Porto Alegre, v. 21, n. 1, p. 229-241, jan./jun. 1996. 
WHITTY, G.; POWER, S.; HALPIN, D. La escuela, el Estado y el mercado. Madrid: Morata, 1999.

ZIZEK, S. Eastern Europe's republics of Gilead. New Left Review, London, n. 183, p. 51-62, set./out. 1990.

ZIZEK, S. Más allá del análisis del discurso. In: LAClaU, E. Nuevas reflexiones sobre la revolución de nuestro tiempo. Buenos Aires: Nueva Visión, 2000. p. 257-267. 